\title{
Monitoring water fluxes in rice plots under three different cultivation methods
}

\author{
Enrico Antonio Chiaradia, ${ }^{1}$ Daniele Ferrari, ${ }^{1}$ Gian Battista Bischetti, ${ }^{1}$ Arianna Facchi, ${ }^{1}$ \\ Olfa Gharsallah, ${ }^{1}$ Marco Romani, ${ }^{2}$ Claudio Gandolfi ${ }^{1}$ \\ ${ }^{1}$ DiSAA, Università degli Studi di Milano, Milano, Italy; ${ }^{2}$ CRR, Ente Nazionale Risi, Castello \\ d'Agogna (PV), Italy
}

\begin{abstract}
Italy is the leading producer of rice in Europe with over half of total production, almost totally concentrated in a large traditional paddy rice area between the Lombardy and Piedmont regions, in the north-western part of the country. In this area irrigation of rice has been traditionally carried out by flooding. The introduction of new combined irrigation and agronomic management practices (dry seeding followed by field flooding and in a full aerobic cultivation with intermittent irrigations), aiming to reduce the water consumption, can determine considerable effect on the landscape and the water cycle. With the aim to study in depth the water fluxes during the whole crop season, three experimental plots at the Ente Nazionale Risi-Rice Research Centre's Experimental Station of Castello d'Agogna (PV) were instrumented. In each plot the following instruments have been installed: 1) a long throated flume and a double shaped (V-notch and rectangular) thin plate for superficial inputs and outputs, 3) a set of piezometers for groundwater levels, 4) one stage level gauge in each submerged field, 5) four tensiometers and moisture sensors clusters, 6) one eddy covariance station for vapour fluxes estimation. Most of the instru-
\end{abstract}

Correspondence: Gian Battista Bischetti, DiSAA via Celoria 2 , 20133 Milano, Italy.

Tel. +39.02.50316904 - Fax: +39.02.50316911.

E-mail: bischetti@unimi.it

Key words: water balance, rice, monitoring.

Contributions: the authors contributed equally.

Conflict of interests: the authors declare no potential conflict of interests Funding: the work was supported by Regione Lombardia under the grants "Fondo per la promozione di accordi istituzionali, "Project "BIOGESTECA" Piattaforma di biotecnologie verdi e di tecniche gestionali per un sistema agricolo ad elevata sostenibilità ambientale.

Acknowledgments: the authors thanks Daniele Masseroni, Ezio Naldi, Gianluca Beltarre and its staff for the field assistance

(C) Copyright E.A. Chiaradia et al., 2013

Licensee PAGEPress, Italy

Journal of Agricultural Engineering 2013; XLIV(s2):e161

doi:10.4081/jae.2013.s2.e161

This article is distributed under the terms of the Creative Commons Attribution Noncommercial License (by-nc 3.0) which permits any noncommercial use, distribution, and reproduction in any medium, provided the original author(s) and source are credited. ments were equipped with electrical sensors connected by cables to a wireless data logger that, in turn, send the data to a PC placed within ENR offices and web-connected by a LAN. In this way, besides the automatic download of data, it was possible to remotely control the devices, to quickly fix troubles, and to better plan the field trips. The management of the whole framework was done by a specifically developed software. In this paper the whole system, which presents some degree of innovation, is described in detail.

\section{Introduction}

Rice cultivation has a great importance in many economies, at the world level and in Italy as well. In Piedmont and Lombardy, in particular, rice represents a significant crop for the whole agricultural sector both in terms of extension and economic value. Although these territories are traditionally rich in water, and agriculture has always been the principal user, in the last years its management is the object of an increasing number of conflicts due to both a growing demand by other stakeholders and new goals related to water quality (Chiaradia et al., 2013).

As the traditional method for rice cultivation requires great volumes of water to keep paddy field flooded, irrigation methods requiring less water have been proposed and increasingly applied (Chiaradia et al., 2013).

In order to study the effect of different rice irrigation systems, the Department of Agricultural and Environmental Sciences - hydraulic group, developed a non-standard and innovative prototypal system for water fluxes monitoring. The system, specifically thought for rice cultivation, has been implemented at the experimental station of the ENRRice Research Center located in Castello d'Agogna-Mortara (Pavia, Italy), This paper describes in detail the prototypal monitoring system.

\section{The monitoring system}

The experimental setup involves three pairs of rice plots. $20 \times 80 \mathrm{~m}^{2}$ in size, each characterized by a different water management strategy (see Figure 1). The monitoring system has been installed in three of the plots, one for each type of irrigation management. These included: i) traditional flooding, ii) dry seeding and delayed flooding, and iii) aerobic cultivation, noted in the course of the paper as T2, T1 and T3, respectively (see Figure 1).

A total of 5 dataloggers, 12 stilling wells for groundwater measurements, 6 device for discharge measurements, 20 tensiometers, 16 of which automatically recorded and connected to the datalogger, 4 soil moisture measurements multilevel probes, automatically read and, finally, an eddy-covariance station were installed. 


\section{Devices and sensors}

\section{Superficial water fluxes}

Inflow discharge for each plot was measured by a RBC long throated flume equipped with a level gauge (Figure 1a). Advantages in using this kind of device are: 1) their hydraulic performance can be theoretically predicted, 2) low level of theoretical error (less than 2\%), 3) little problem with sedimentation (Clemmens et al., 2001); in addition, long RBC flumes work well also with small upstream head values that was one of the constrains of this installation. The RBC flumes were built by a $1.26 \mathrm{~m}$ long metal sheet trapezoidally shaped in section. Channel base is $0.09 \mathrm{~m}$ large and walls are inclined of $63.4^{\circ}$. Throat was obtained by a trapezoidal element at the bottom of the flume. A stilling well was connected by a PVC tube to the upstream section and two metal walls increased the handcraft stiffness. Discharge scale was calculated using the WinFlume software version num. 1.06.0004 (www.usbr.gov/pmts/hydraulics_lab/winflume) and verified by volumetric sampling. Attention was given in placing correctly the base of flumes with respect to the seed bed to avoid backwater when fields were flooded.

Triangular V-notch weirs were instead used to measure outflow discharge (Figure 1b). Weirs were installed on a metal box $1.2 \mathrm{~m}$ long, 1.0 $\mathrm{m}$ width and $0.4 \mathrm{~m}$ height. At the internal side of the box a woody gate was used to regulate water depth inside paddy fields. A stilling well was placed in the middle of a lateral wall of the box. The outflow from the box passed through a mobile $\mathrm{V}$ shaped plate able to measure low discharges (less than $5 \mathrm{l} / \mathrm{s}$ ), whereas during high flow (up to $30 \mathrm{l} / \mathrm{s}$ ) the plate was removed and the weir became rectangular. Both the sections have been associated to a specific stage-discharge relationship, calibrated by some volumetric tests.

Both flumes and V-notch weirs, have been equipped with pressure transmitters for industrial applications (serie $41 \mathrm{X}$ by Keller, www.keller-druck.com) to measure the water level within the stilling wells . The sensors have a full scale, FS, of 30 mbar (relative pressure), i.e. $30.6 \mathrm{~cm}$ of water, and an error 0.1-0.2 \% FS (i.e. $<1 \mathrm{~mm}$ ). Measures were recorded every 10 minutes.

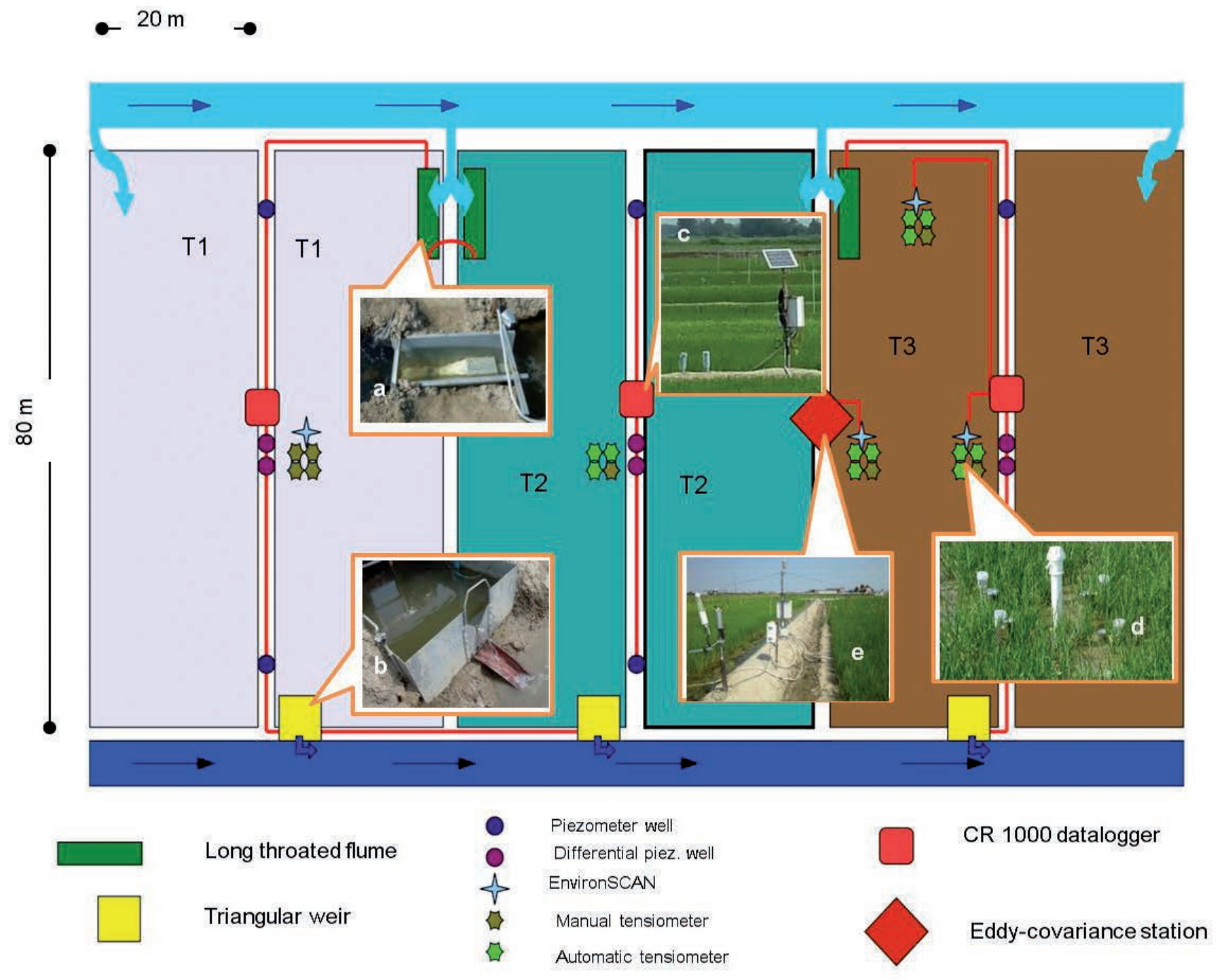

Figure 1. Diagram of the experimental plant: T1, T2 and T3 are the three different treatments, duplicated in two field of $40 \times 80 \mathrm{~m}$. a) long throated flume, b) V-shaped weir, c) the heads of the piezometer tubes and the datalogger system, d) a cluster of tensiometer and one moisture sensors column, e) eddy covariance station. 


\section{Ground water levels}

Ground water levels were monitored in 12 1"1/5-piezometric wells (Figure 1c). The wells were positioned along the levees dividing two paired plots with the same treatment (Figure 1). Along each levee, the two wells positioned at upstream and downstream sides of the plot have a $1.5 \mathrm{~m}$ long windowed tube, whereas the central couple of wells had a smaller windowed segment of $0.10 \mathrm{~m}$ positioned at 3 and $1.5 \mathrm{~m}$ in depth. The central wells are used as differential piezometer. Each piezometer was endowed by a pressure transmitter PR-46X by Keller with 100 mbar FS $(1.02 \mathrm{~m})$ and error less than 0.1\% FS (1.02 mm). Measures were recorded hourly.

\section{Soil water content and potential}

Soil water content was measured by 4 EnviroSCAN (Sentek Pty. Ltd., South Australia) sensors. EnviroSCANs are multiple sensor capacitance probes capable of continuous measurement of soil moisture; in the present case four depths, 10, 30, 50, $70 \mathrm{~cm}$, were set (Figure 1d).Volumetric water content is obtained by a scaled frequency reading using a site specific calibration equation. Calibration tests were made by volumetric measures on undisturbed soil volumes sampled at the end of the season.

The soil moisture tension was measured by tensiometer devices (Figure 1d). A total of 5 groups of tensiometers for a total number of 20 were installed in clusters, 12 of which able to automatically record the data. In each cluster, tensiometers were placed at a different depth: 10, 30, 50 and $70 \mathrm{~cm}$ respectively, the same depths monitored by EnvironSCAN sensors. The data were recorded every 10 minutes.

\section{Aerial water fluxes}

A 3D sonic anemometer, model num. 81000 (Young Co., 2010) and an infrared gas analyser, model LI-7500 (LI-COR, 2009) for the measurement of energy and gas $\left(\mathrm{H}_{2} \mathrm{O}, \mathrm{CO}^{2}\right)$ exchanges were installed on the levee separating the two irrigation treatment T3 and T2, as shown in Figure 1e. This in order to monitor two rice treatments with only one eddy covariance station; this was possible because the limited size of the experimental fields. Instruments were held at one meter over the average canopy height, changing the vertical position of the sensors, during all the monitoring period (18 July - 21 September 2012). Net radiometers CNR-1 (Kipp \& Zonen, 2002) and devices for the measurements of the heat flux in the soil were installed in both fields. In particular, one heat flux plate HFP01 (Hukseflux, 2010) for each irrigation treatment was installed at $8 \mathrm{~cm}$ below the soil surface. Two soil thermocouples (Campbell, 2012a), installed at 2 and $6 \mathrm{~cm}$, allowed the calculation of the ground heat flux ( $\mathrm{G}$, in $\mathrm{W} \mathrm{m}^{-2}$ ) at the soil surface for the intermittent irrigation treatment (T3). As G calculation required an accurate set-up on the flooded rice field, the challenge was to measure the storage term ( $G$ ) in the water. To do that, in addition to the two soil thermocouples, also the water temperature and the water level in the field T2 were measured over time by means of a pressure transmitter (serie 41X by Keller, www.keller-druck.com). A thermohygrometer (Vaisala, 2006) completed the installation. The data were recorded every 30 minutes.

\section{Acquisition and storing system}

The number of dataloggers were defined according to: 1) total number of sensors, 2) maximum cable length to limit noise and voltage loss, 3) permitting machines passage for cultivation works, 4) best distribution of recording work between each instrument, 5) costs of the instruments.

Three CR1000 and one CR5000 Campbell Scientifics dataloggers (Campbell, 2012b) were installed on each of the three instrumented

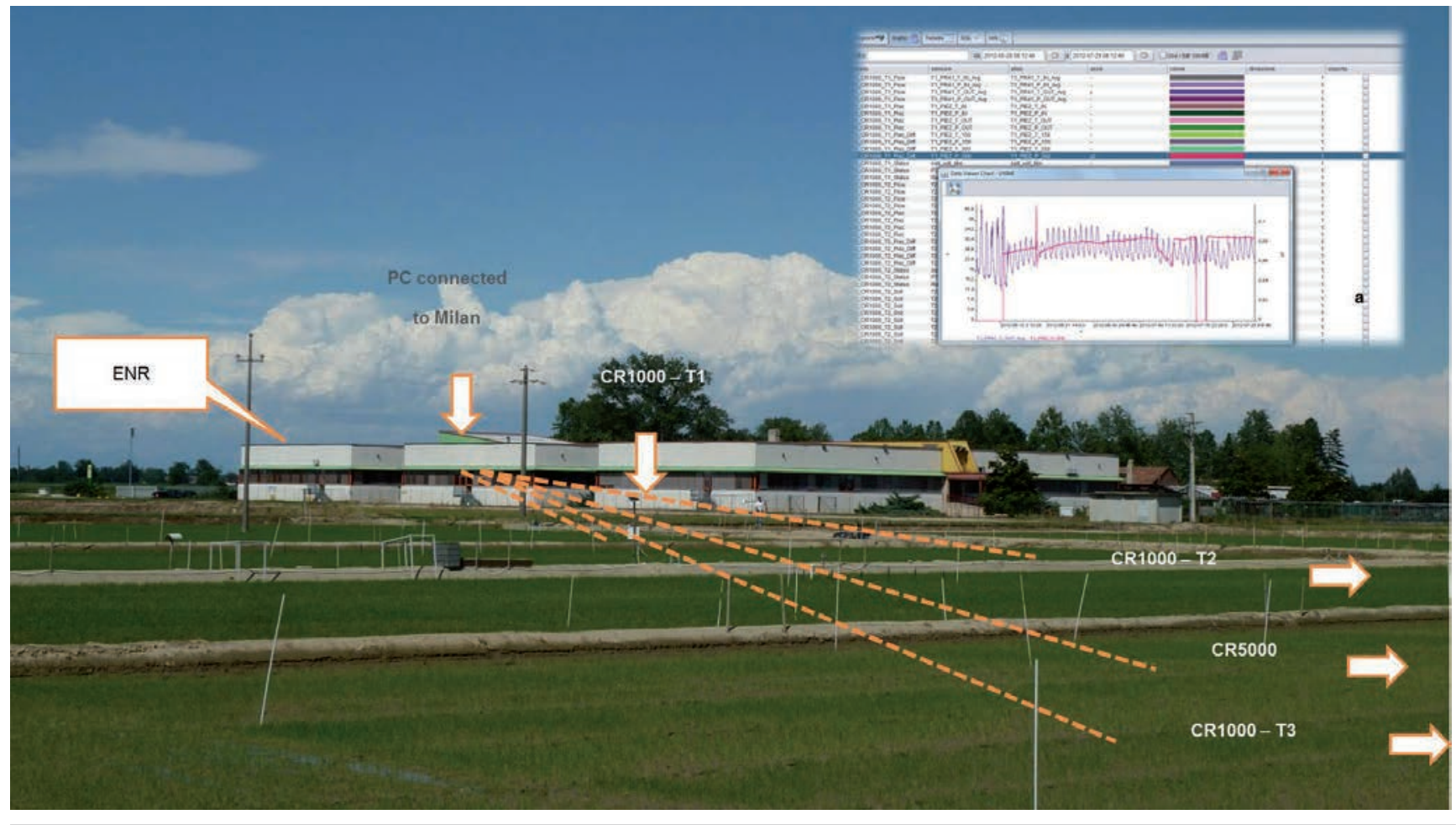

Figure 2. A view to the ENR building in Castello d'Agogna (PV); dashed lines describe theradio connections between dataloggers and the PC positioned in the office; a) an example of the custom made Java software. 
levee and for the Eddy Station (Figure 1c). Each CR1000 DL can manage up to 16 single-ended analog input channels, 2 pulse input and 8 digital ports, whereas CR5000 DL 40 single-ended analog input channels, 2 pulse input and 8 digital ports.

Each datalogger was powered by a $12 \mathrm{~V} / 12$ Ah rechargeable sealed lead-acid battery automatically recharged by a standard solar panel (CanadianSolar Mo. Type CS5F-14M) with a nominal maximum power of $14 \mathrm{~W}$ through a $12 \mathrm{~V}$ charge controller (Steca Solsum 8.8F). All groups were protected by an industrial control panel enclosure (Stahlin).

Finally, a set of tensiometer was controlled by a standalone datalogger Watchdog 2000 series (Spectrum, 2009).

\section{Remote control, backup and data analysis}

All dataloggers were wireless connected, through a RF416 radio (Campbell, 2011), to a RF432 radio (Campbell, 2011) installed on a PC placed in one of the offices in the ENR building. All the radio were cou- pled with a $0 \mathrm{dBd}, 1 / 4$ wave whip antenna (model num. 15730, Campbell, 2011).

The storing procedure was programmed by the software LoggerNet 4.3.1 (Campbell, 2012c). Connection was operating every day from 8.00 a.m. for data download and storage (Figure 2). An automatic procedure produced, every day after the download, a compressed backup file of the stored data that were sent via FTP to a remote storage device in Milan by standard web network.

The PC at ENR was remotely controlled and, besides downloading data, permitted to check the system operation at any time, limiting the number of direct visits and the data loss.

To manage the huge quantity of data, a custom graphical software written in Java language and supported by SQLite database, have been developed to provide a complete framework for rapidly data visualization, queries, post-acquisition correction and exportation to text file (Figure 2a).

Table 1. Cost of instrument and sensors installed during the research activity.

\begin{tabular}{|c|c|c|c|}
\hline material & individual cost $(€)$ & Number & Total cost $(€)$ \\
\hline $\begin{array}{l}\text { Keller pressure sensor } 41 \mathrm{X} \\
\text { Material for RBC flumes and V-noch weirs }\end{array}$ & $€ 310,00$ & $\begin{array}{c}8 \\
€ 1.138,51\end{array}$ & $€ 2.480,00$ \\
\hline Surface flow & & & $€ 3.618,51$ \\
\hline $\begin{array}{l}\text { Keller pressure sensor PR-46X } \\
\text { Piezometer wells } \\
\text { USB-driver for Interface converter K-104 } \\
\text { Additional cables }\end{array}$ & $\begin{array}{l}€ 300,00 \\
€ 80,00\end{array}$ & $\begin{array}{c}12 \\
€ 531,19 \\
1 \\
€ 228,00\end{array}$ & $\begin{array}{l}€ 3.600,00 \\
€ 80,00\end{array}$ \\
\hline Groundwater & & & $€ 4.439,19$ \\
\hline $\begin{array}{l}\text { EnviroSCAN } \\
\text { Tensiometers Irrometer con manometro, } \\
\text { Pressure transducers for tensiometers } \\
\text { Pressure transducers for tensiometers }\end{array}$ & $\begin{array}{l}€ 2.400,00 \\
€ 150,00 \\
€ 350,00 \\
€ 392,00\end{array}$ & $\begin{array}{c}4 \\
20 \\
2 \\
4\end{array}$ & $\begin{array}{l}€ 9.600,00 \\
€ 3.000,00 \\
€ 700,00 \\
€ 1.568,00\end{array}$ \\
\hline Soil water & & & $€ 14.868,00$ \\
\hline $\begin{array}{l}\text { 3D sonic anemometer } \\
\text { Infrared gas analyser } \\
\text { CGR } 3 \text { pyrgeometer } \\
\text { CMP } 3 \text { pyranometer } \\
\text { Heat flux plate HFP01 } \\
\text { Thermocouples }\end{array}$ & $\begin{array}{l}€ 7.500,00 \\
€ 18.120,00 \\
€ 1.300,00 \\
€ 760,00 \\
€ 512,00 \\
€ 53,00\end{array}$ & $\begin{array}{l}1 \\
1 \\
1 \\
1 \\
1 \\
2\end{array}$ & $\begin{array}{l}€ 7.500,00 \\
€ 18.120,00 \\
€ 1.300,00 \\
€ 760,00 \\
€ 512,00 \\
€ 106,00\end{array}$ \\
\hline Eddy station & & & $€ 28.298,00$ \\
\hline $\begin{array}{l}\text { CR1000 } \\
\text { CR5000 } \\
\text { Case } \\
\text { Mast Mount bracket } \\
\text { Interfaccia SDI-12 per sonde EnviroSmart } \\
\text { Modulo I/O a } 1 \text { canale seriale, protocollo RS232, } 485 \text { e } 422 \text { (NO CR5000) }\end{array}$ & $\begin{array}{l}€ 1.438,00 \\
\quad 1 \\
€ 270,00 \\
€ 79,00 \\
€ 438,00 \\
€ 210,00\end{array}$ & $\begin{array}{c}3 \\
€ \\
3.500,00 \\
3 \\
3 \\
3 \\
3\end{array}$ & $\begin{array}{l}€ 4.314,00 \\
€ 810,00 \\
€ 237,00 \\
€ 1.314,00 \\
€ 630,00\end{array}$ \\
\hline Data logger & & & $€ 10.805,00$ \\
\hline $\begin{array}{l}12 \mathrm{~V} / 12 \text { Ah rechargeable sealed lead-acid battery } \\
14 \mathrm{~W} \text { solar panel } \\
\text { SOLSUM8.8 Regolatore di carica 8.8A Solsum }\end{array}$ & $\begin{array}{l}€ 65,00 \\
€ 27,30 \\
€ 31,20\end{array}$ & $\begin{array}{l}3 \\
6 \\
3\end{array}$ & $\begin{array}{l}€ 195,00 \\
€ 163,80 \\
€ 93,60\end{array}$ \\
\hline Power supply & & & $€ 452,40$ \\
\hline $\begin{array}{l}\text { RF416 radio } \\
\text { RF432 radio } \\
\text { Whip antenna }\end{array}$ & $\begin{array}{l}€ 466,00 \\
€ 486,00 \\
€ 35,00\end{array}$ & $\begin{array}{l}3 \\
1 \\
4\end{array}$ & $\begin{array}{l}€ 1.398,00 \\
€ 486,00 \\
€ 140,00\end{array}$ \\
\hline Remote transmission & & & $€ 2.024,00$ \\
\hline $\begin{array}{l}\text { Cables, } \\
\text { Connectors and other material }\end{array}$ & & $\begin{array}{l}€ 708,29 \\
€ 597,00\end{array}$ & \\
\hline
\end{tabular}

Cables, etc.

Shadowed cells indicate that instruments and sensor were already available for the research. 


\section{Costs and work}

To establish the described system, instruments and sensor already available to group and new bought ones were used. In Table 1 are reported costs of the instruments, sensors and other material required for installing the system. It can noted that the whole value of instrumentation is approximately 65,000 euros, $64 \%$ of which already available to the research activity. Among the different components of the system nearly half is imputable to gas fluxes measurement, approximately $20 \%$ to soil tension and soil water content measurement and approximately $15 \%$ to data loggers; surface flow and groundwater measurement, and data transmission, power supply and consumables required only few per cent of the total investment.

In terms of human effort, it is not easy carrying out an accurate estimate, also due to the number of people involved in the different activities (7 people). It was impossible tracing the time spent in choosing the right combination of instruments and in programming the sensor and data loggers in laboratory. A rough (underestimated) evaluation of in-field only activity gives a value of 67 man-days; 29 for the system installation, 24 days for management during the crop season, 14 day for removing the system to allow field operations to the new season.

As such data refer to the first experience in installing the system, it is expected that some time could be save for a new installation (approximately a half). On the contrary, no time can be expected to be saved during the season and in removing the system.

\section{Conclusions}

An experimental setup for the integrated monitoring of the water fluxes in three rice plots, using a variety of sensors and probes, has been presented in the paper. If on one hand the use of single sensors and probes does not represent a novelty, on the other their use in a such massive and synergic way was a challenge in practice. In such a perspective, the possibility to verify if all the instruments were working correctly from remote, without the necessity to visit daily the experimental plots represented a crucial point in limiting the loss of data and in reducing the research costs. Much effort was spent in choosing the right combination of instruments in order to guarantee the proper connection and communication between sensors and dataloggers over a local net and using different protocols. Most of the sensors, in fact, are from different manufacturers, each with its own communication protocol an then requiring a hard work to make them connected without conflicts. Problems related to energy supplies, noises in the acquisition, remote connectivity and limits due to the environmental characteristics (high temperature and high humidity) required a great attention as well.
After a first season of monitoring activity, a nearly complete set of data were obtained from field measurements: maximum data losses amounted to $9.4 \%$ in all the monitored period.

The first years' experience suggested some adjustments, which were considered for the current season (2013). All the system, in fact, have to be removed before the new season to allow ploughing and all the operations for the cultivation,

For example, triangular weirs have been substituted by RBC flumes similar to those installed for inflow monitoring as the latter are easier to be placed and to calibrate. The pressure sensors for water level measure inside the flumes, have proven to better work when horizontally installed instead of vertically (as suggested by their datasheets) in order to prevent any possible presences of air balls inside the threaded pin during very high temperature values. During the first year we had, in fact, some problems due to such phenomenon and a specific post processing algorithm had to be developed to remove the errors.

A new monitoring season is currently undergoing and already resulted in strongly reduction of installation time.

\section{References}

Campbell, 2011. RF401-Series \& RF430-Series Spread Spectrum Radio Modems. www.campbellsci.com

Campbell, 2012a. Model 108 Temperature Probe Instruction Manual. www.campbellsci.com

Campbell, 2012b. CR1000 Measurement and Control System Operator's Manual. www.campbellsci.com

Campbell, 2012c. LoggerNet Version 4.1 Instruction Manual. www.campbellsci.com

Clemmens A.J., Wahl T.L., Bos M.G., Replogle J.A., 2001. Water measurement with flumes and weir. International Institute for Land Reclamation and Improvement / ILRI, Wageningen, The Netherlands.

Chiaradia E.A., Facchi A., Gharsallah O., Romani M., Bischetti G.B., Gandolfi, C. 2013. Water balance of rice plots under three different cultivation methods: first season results, Proceedings of AIIA 2013, Viterbo (Italy), September 8-12 2013.Kipp \& Zonen, 2002. CNR- 1 Net radiometer Instruction Manual. www.kippzonen.com

Hukseflux, 2010. HFP01 Heat flux plate/ heat flux sensor (Brochure). www.hukseflux.com

Vaisala, 2006. Vaisala HUMICAP® Indicator HMI41 and Probes HMP41/45/46 Vaisala User's guide. http://www.vaisala.com.

LI-COR, inc., 2009. LI-7500A Open Path CO2/H2O Analyzer Instruction Manual.

Young Co., 2010. Ultrasonic anemometer Model 81000 Instructions. www.youngusa.com

Spectrum, 2009.Watchdog 2000 Series Weather Stations product manual. www.specmeters.com 